\title{
Perceptions of cascading risk and interconnected failures in emergency planning: implications for operational resilience and policy making
}

Author: Gianluca Pescaroli, University College London.

\begin{abstract}
Cascading events and the disruption of interconnected critical infrastructure $(\mathrm{Cl})$ are a well-known challenge for emergency planning and management. Although new modelling and forecasting tools are increasing the availability of mitigation options, further work is needed to consolidate good policies and practices.

This paper presents a case study on London, United Kingdom (UK). It develops an integrative research process with local stakeholders aimed at applying the theory of cascading disasters in London's response and preparedness strategies. A mixed method approach is adopted to explore the awareness of cascading risk, the perception of possible mitigation measures, and the current levels of training amongst the stakeholders of the London Resilience Partnerships. Specific items investigate the relation of cascades with cross- border crisis management, and climate change.

The results propose new quantitative and qualitative evidence that highlights the divergence between risk awareness and its integration in policies and practices, discussing options for improving multiagency coordination and organisational resilience. The conclusions define a list of actions that should be strategic priorities for policies and decision makers, such as the improvement of inter-modal coordination and the release of open access guidelines, proposing new open questions for scholars in the field.
\end{abstract}

\section{Introduction}


The complexity of networked society and the uncertainties inherent in emerging threats, such as geomagnetic storms, are challenging our approach to crisis management. It has been suggested that extreme scenarios could be more common than was previously supposed, requiring a new understanding of their drivers (Sornette 2009). However, those challenges involve the whole anthropogenic domain and cannot just be associated with specific hazards. It is known from the "normal accidents" theory that interdependent technological systems are prone to multiple and unexpected failures that can trigger cascading disruptions (Perrow 1999). Events such as the failure of telecom satellite Galaxy IV (1998) and the North America Blackout (2003), highlighted the need for improving the protection and resilience of critical infrastructures $(\mathrm{Cl})$, intended as those systems or assets that are vital for social functions (Setola et al. 2016). The multiple domains of $\mathrm{Cl}$ were recognised both in terms of hardware and services, including their interdependencies with all ordinary activities of life (Little 2002; Rinaldi et al. 2001). It became clearer that $\mathrm{Cl}$ failures could generate widespread breakdowns beyond the conventional organizational and hierarchical borders (Boin and McConnell 2007; Egan 2007; Helbing et al. 2006). However, the cascading dynamics associated with those patterns remained fragmented in literature and practices (May 2007), and scholars often concentrated on models that were limited by the absence of testing in real-life scenarios (Peters et al. 2008).

The state of the art evolved after some high -impact events in the early 2010s, such as the eruption of the Eyjafjallajökull volcano, and the challenges associated with climate change scenarios. It was more visible that the increased complexity of global networks challenged governance, jurisdictions, organisational and societal resilience (Alexander 2013; Ansell et al. 2010; Galaz et al. 2011; Labaka et al. 2016; Parker 2015; Setola et al. 2016). Thus, it was suggested that a paradigm shift in safety and risk analysis strategies was urgently needed to improve the adaptive capacity to complex challenges (Helbing 2013; 2015; Linkov et al. 2014). Further steps in understanding cascading and interconnected dynamics has been supported by the EU $7^{\text {th }}$ Framework Programme and Horizon 2020, evolving forecasting tools and decision support systems (Galbusera et al. 2016; Jonkeren et al. 2015; Setola et al., 2016). Other complementary approaches evolved from $\mathrm{Cl}$ modelling, including cross-cutting contingency planning and scenario building. It was considered that cascading disasters could be associated with complex and evolving secondary emergencies, which tended to become the centre of the crisis (Pescaroli and Alexander 2015). That process is multi-dimensional. It includes: $A$ ) the losses of vital services due to the shifting states of operations in the $\mathrm{Cl}$, from routinely to stressed (Nieuwenhuijs et al. 2008); B) The impact of external triggers on hazardous facilities (Argenti et al. 2016; Krausmann and Baranzini 2012); C) The cross-scale challenges involving socio-ecological systems (Galaz et al. 2011). It has been suggested that these cascades require a shift in scenario building and training, focusing on the escalation of secondary events to increase the flexibility in situations of operational uncertainty (Pescaroli and Alexander 2016). First, it has been recognised that $\mathrm{Cl}$ disruptions can orient international relief by causing a shortfall of goods and expertise associated with the loss of services, NATECH emergencies, and damages to cultural heritage (Pescaroli and Kelman 2017). Secondly, it had been shown that risk maps have to be integrated with critical infrastructure rankings, promoting the development of cross-scale assessments of socio-ecological vulnerabilities (Nones and Pescaroli 2016). Thirdly, vulnerability scenarios could be used in new tools to enhance the capacity of local communities to be resilient to complex events such as blackouts (Münzberg et al. 2017). In conclusion, it is essential to introduce best practices in emergency planning that could frame together the different components of risk, 
referring to the possibility of unexpected paths (Alexander 2016). It has been shown that the vulnerabilities in the technological component of $\mathrm{Cl}$ could be coincident between natural and human-made risks, being also common to other triggers that are unknown, or at least highly uncertain, with the potential of compromising or challenging emergency management (Pescaroli et al. 2018).

A gap that has not been investigated is how cascades, interdependencies and escalations are perceived by $\mathrm{Cl}$ stakeholders and emergency managers and which could be the implications for preparedness. Specific procedures, such as wider impact trees, have been adopted by some governmental bodies in charge of standards for organisational resilience (Macfarlane 2015), but are these lessons really incorporated in practices? The literature suggests there could be still a lack of understanding of $\mathrm{Cl}$ dependencies amongst emergency planners and responders, increasing the impact of emergencies (Luiijf and Klaver 2009; 2013). Indeed, the complexity of cascading effects can challenge the existing knowledge of emergency personnel, as well as their faimiliarity with the possible evolutions of the events, increasing the disturbances and the uncertainties in decisions (Amon et al. 2016).

This paper aims to investigate this area of risk perception (Slovic and Weber 2002), supporting with new quantitative and qualitative data the development of a consistent framework for cascading risk in policy making. We apply an integrative research process with the local institutions to link knowledge into action, considering how to improve decision making under high uncertainties (Cornell et al. 2013; Wardekker et al. 2008). The goal is to verify if cascading risk and interconnected failures are sufficiently addressed in the multi-agency planning assumptions of Greater London. This case study is relevant for the state of art because London's infrastructure and society are highly integrated in the global networks, concentrating some of the financial and transportation hubs in the region. In the next sections the applied nature of the research is explained, including the synergies with the authorities, the research precursors, and the key questions investigated. In the second instance, the methodology adopted for the assessment is described, and the results are illustrated highlighting the implications for the current multi-agency response capacity. In conclusion, possible mitigation actions and guidelines for policy makers are suggested.

\section{Integrative research process}

This work is a result of a collaboration between the Research Group on Cascading Disasters at the UCL Institute for Risk and Disaster Reduction (CASCADES@IRDR), and London Resilience (LR). LR acts on behalf of the Mayor of London, Greater London Authority, Local Authorities and London Fire Brigade. It aims to coordinate institutions and communities to "prevent, handle, recover and learn from disruption, and adapt to change" (www.londonprepared.gov.uk). The London Resilience Partnership (LRP) includes more than 170 organisations involved in emergency response and preparedness in London, United Kingdom (UK). In 2012, LR developed ANYTOWN, a generic and replicable model used to "raise awareness of the consequences of infrastructure disruption with all emergency response organisations in London" (Hogan 2013). It is structured to be applied easily in most cities using workshops that produce evidence on the typical impacts of disruptions regardless of their initial trigger. The effects of hypothetical failures are reported in an onion-skin diagram including both short- and longer-term effects, communicating the message in a way accessible for non-academic audience. The complementarities of the work of 
CASCADES@IRDR suggested promoting a data collection at the ANYTOWN workshop in March 2017. The event was organised by LR, in collaboration with the London Climate Change Partnership (LCCP), the UCL Institute for Risk and Disaster Reduction, and with support from Transport for London (TfL). It was held at the London City Hall to "consider the broader consequences resulting from a disruption to transport networks", and it was closed -doors. The invitations were sent to the members of the Partnership, such as emergency response organisations, public utilities, businesses, and academia. ANYTOWN was organised in two half day sessions, in the morning and the afternoon, with a cap on the number of participants to assure an active discussion. In each session, an introduction to the workshop explained the ANYTOWN model, the concept of cascading effects and disasters as reported by Pescaroli and Alexander (2015), and London's strategy for adapting to climate change. A short overview of the scenario was followed by roundtables. The trigger hazard was a hypothetical heat wave, whose features were derived from the existing literature (Birkmann et al. 2014). However, facilitators of LR were present at each table and encouraged the participants to focus on the possible interdependencies, cascading effects, and escalations. A complementary methodology was used to assess the multi-agency response and preparedness capacity and it will be explained in the next section.

\section{Methodology}

The methodology was developed with a constant dialogue between CASCADES@IRDR, LR, and the LCCP that allow maintaining a reliable interface between science and policies (Cornell et al. 2013; Wardekker et al. 2008). First, it had to be replicable in future workshops, being complementary to the output of the discussion groups. Secondly, it had to provide quantitative evidence for policy-makers, integrating possible feedbacks of the participants. In conclusion, the data collection had to target a mixed audience with limited time availability. It was chosen to relay on questionnaire as common practice in the assessment of risk perceptions, civil protection programs, and emergency management at large(Abrahamsson et al. 2010; Alexander 2002; 2005; 2015; 2016; Lindell et al. 2007; Perry and Lindell 2003; Quarantelli 1997; Slovic and Weber 2002). The questions followed the standard approach of quantitative research (Bryman 2012; Van Evera 1997), and were analysed with SPSS V.24. However, the participatory nature of the workshop and the complexity of the topic suggested integrating a mixed method approach to record the bottom up perspectives of the LR Partnership (Axinn and Pearce 2006; Palinkas et al. 2011). Each section of the survey included open questions for the respondents: they asked for suggestions about possible mitigation measures, training strategies, general comments on the workshop, and on who should assure the consistency of information. Those answers were investigated with a qualitative content analysis, using together inductive and deductive considerations (Berg 2004). The categories were cross- checked with LR to verify their consistency with the operational and legislative terminology in use. The main hypothesis was that if the current crisis management approach to cascading risk was inadequate, then it was expected that the answers could highlight:

1) A strong awareness of cascading risk and interconnected failures, not adequately supported by policies and planning strategies.

2) High values attributed to most mitigation measures, and average integration of longer term climate change in planning. 
3) Lack of consistent training, with high values attributed to all the possible tools suggested. The next section describes the design of the questionnaire before proceeding to the analysis of data.

\subsection{Questionnaire design}

Questions and answers were discussed with LR, and the LCCP, as suggested in the integrative research process. The items were formulated together to limit possible sectorial biases and ambiguities. The output was tested with a pilot involving the LR team that verified the consistency of the terminology for the target audience of the workshop. Similarly, the visual layout of the questionnaires was checked with pre-printing to avoid a lack of clarity that could limit the response rate (Boynton and Greenhalgh 2004). It was agreed a five page questionnaire, including the introduction, that required approximately 5-10 minutes to be completed on a self -administered basis. The first page reported a standard disclaimer that specified the goal of the research, the referents, and guaranteed the anonymity and privacy of the respondents. The questionnaires were structured in four sections:

$\checkmark$ Section 1 - Stakeholders' perception of cascading events and interdependencies. This section explored the awareness of cascading risk, its relationship with other drivers such as climate change, and the actual prioritisation in policies and practices.

$\checkmark$ Section 2 -Stakeholders' opinion about mitigation strategies. This section investigated the perceived utility of existing mitigation measures and the potential of other tools suggested in the literature. At the end of this section the participants were asked to write down suggestions about possible mitigation measures that should be prioritised and were not included in the list.

$\checkmark$ Section 3 - Stakeholders' opinion about training related to cascading events and interdependencies. This section assessed the existing levels of training, and which training measures could be more useful. At the end of this section the participants were asked to write down possible training other than the one listed.

$\checkmark$ Section 4 - Stakeholders' experience and affiliation. This section asked general questions about experience, affiliation, gender and perceived utility of the workshop. Those values were needed to correlate the results, promoting more focused policies. There was space left for general comments.

The existence of validated and published surveys was considered for the formulation of each item (Boynton et al. 2004). In the preliminary phase of the design, the possible literature of reference was listed in a descriptive table as suggested by Brugess (2011), then it was discussed with the stakeholders. However, this process was limited by the scarcity of studies linking cascading disasters, emergency preparedness, and training: more than replying to specific questions and results, it was possible to derive possible options generically identified in the literature that had to be tested. The reference for "Section 1" was mostly the references reported in the introduction and methodology of this paper, while in "Section 4" were considered standard drivers of risk perceptions that were also needed by LR as generic data on the workshop. "Section 2" and "Section 3" integrated cross-cutting considerations on mitigation and training. The researches on sectorial failures and cascades, both generic and case-specific specific, suggested testing different mitigation options. In particular, it was possible mitigation role of scenario building and contingency planning (Alexander 2016; 
Pescaroli and Alexander 2016), integration of hazard risk with rankings of $\mathrm{Cl}$ (Nones and Pescaroli 2016), datasets to improve fast deployment of emergency response (Gianluca Pescaroli and Kelman 2017), and decision support systems (Setola et al. 2016). The evidence of the 2010 ash cloud highlighted issues in the reliability of thresholds in probabilistic data, communication and information sharing, and intramodality (Alexander 2013; Scaini et al. 2015; Ulfarsson and Unger 2011). Localized and improved energy supply were also suggested as possible priorities for policy makers, together with the need of considering international mitigation strategies and climate change drivers in planning and activities (Ansell et al. 2010; CAA 2014; Galaz et al. 2011; Helbing, 2015; OECD, 2011; Petermann et al. 2011). The possible training options referred to the ones available by the UK Cabinet Office's Emergency Planning College (Macfarlane 2015), and more in general feasible to be implanted by LR. Table 1 reports the final questions used for the questionnaires, including their section and the number of reference. The multiple items are highlighted in grey, while the open items that allowed discretionary answers in yellow. A standard Likert scale, from 1 (not at all) to 5 (extremely) was used for most items, and reported both qualitatively and quantitatively according to conventions in the assessment of civil protection and emergency management s (Alexander 2015,Bryman 2012, Lindell et al. 2007). The synthesis by Brown (Brown, 2010) was used for maintaining the correspondence between the numeric and qualitative values. Moreover, the awareness of specific tools and experience in training (Q18 a, b and Q22) was assessed using polar questions (yes/no). Three answers (Q13, Q21, and Q23) required the development of new categories:

$\checkmark$ Q13 tested which organisations should be in charge of information in line with the protocols of LR, with a multiple answer that wanted to test collective versus individual responsibilities. The categories were derived by the work of Lindell et. al. (2007), Perry and Lindell (2003), but included a UK perspective that referred to the grey area of stranded passengers (CAA 2014). The possibility of an open answer was included, as has been reported in Table 1.

$\checkmark$ Q21 asked for the respondents' experience and seniority level, but a clear and appropriate scale was not found in the literature. It was derived approaching a standard definition used by human resources online (University of Virginia 2016), which were cross-checked with the feedbacks of the LR team and LCCP (Table 1).

$\checkmark$ Q23 asked to define the respondents' affiliations, which had to be focused on the members London Resilience Partnership. To mediate possible cultural divides, it was decided to integrate the categories used by Lindell, Prater, and Perry (2007), with the one described by the UK legislation for emergency management (UK Cabinet 2013).

In conclusion, it must be noted that questionnaires were distributed in each discussion table at the beginning of the event. This was supported by a short explanation by LR and CASCADES@IRDR, where it was highlighted the value, the simplicity, and the limited time commitment needed for the contribution. It was emphasised that the essential findings will be included in the final report of the event (Burgess 2001), and that the research was finalised to improve the coordination of the LRP. The next sections of this research will explore the quantitative and qualitative results of the analysis. The possible limitations of the research will be included in the discussion section to derive open points for future researches to be included in the conclusions. 


\begin{tabular}{|c|c|c|}
\hline \multicolumn{3}{|r|}{ Table 1 - Sections and questions of the survey } \\
\hline Section & N. & Question \\
\hline \multirow{9}{*}{$\begin{array}{c}\text { Section1 } \\
\text { Perceptions of } \\
\text { cascading } \\
\text { events and } \\
\text { interdependencies }\end{array}$} & Q1 & How relevant are cascading events to emergency management? \\
\hline & Q2 & $\begin{array}{l}\text { Do you think loss of essential services can cause risks to life and personal safety } \\
\text { or security? }\end{array}$ \\
\hline & Q3 & To what extent are service disruptions catered for in UK emergency planning? \\
\hline & & To what extent do you think cascading events and interconnected failures are: \\
\hline & Q4a & Prioritised in existing policies? (e.g. multi-agency response frameworks) \\
\hline & Q4b & Prioritised in practice? (e.g. stakeholder interoperability) \\
\hline & Q4c & $\begin{array}{l}\text { Integrated in agreements for cross-border crisis management? (e.g. activation } \\
\text { and deployment of the EU civil protection machinery) }\end{array}$ \\
\hline & Q5 & $\begin{array}{l}\text { Would a common definition of 'tipping points' and definitions of acceptable risk } \\
\text { and uncertainty be helpful in coordinating emergency response? }\end{array}$ \\
\hline & Q6 & $\begin{array}{l}\text { Do you think cascading events could become more common as a result of } \\
\text { climate change? }\end{array}$ \\
\hline \multirow{12}{*}{$\begin{array}{l}\text { Section } 2 \\
\text { Opinion about } \\
\text { mitigation } \\
\text { strategies }\end{array}$} & & $\begin{array}{l}\text { How helpful do you think the following tools could be in understanding cascading } \\
\text { events? }\end{array}$ \\
\hline & Q7a & Scenario building \\
\hline & Q7b & Contingency planning \\
\hline & Q8 & $\begin{array}{l}\text { Do you think information on the resources available to combat service } \\
\text { disruptions could be used to improve procurement strategies and the } \\
\text { deployment of aid and relief? (e.g. ready-to-eat meals supplied after } \\
\text { blackouts) }\end{array}$ \\
\hline & Q9 & $\begin{array}{l}\text { Do you think it could be useful to integrate hazard risk with rankings of the criticality } \\
\text { of infrastructure? }\end{array}$ \\
\hline & Q10 & $\begin{array}{l}\text { Do you think improving coordination among different transport modes should be a } \\
\text { priority in order to mitigate large-scale disruption? }\end{array}$ \\
\hline & Q11 & $\begin{array}{l}\text { Do you think more localised energy sources could improve the resilience of critical } \\
\text { infrastructure? }\end{array}$ \\
\hline & Q12 & $\begin{array}{l}\text { How useful are interactive tools and real-time decision support systems to } \\
\text { understand the effects of cascading disruptions? }\end{array}$ \\
\hline & Q13 & $\begin{array}{l}\text { In the case of service disruptions, who do you think should assure the consistency } \\
\text { of information given to the public? (One option has open answer) }\end{array}$ \\
\hline & Q14 & $\begin{array}{l}\text { Do you think cascading events and associated service disruptions require the } \\
\text { development of international mitigation strategies? }\end{array}$ \\
\hline & Q15 & Are you considering longer-term climate change in your planning and activities? \\
\hline & Q16 & $\begin{array}{l}\text { Is there anything else that has not been mentioned that should be prioritised? } \\
\text { (Open answer) }\end{array}$ \\
\hline \multirow{11}{*}{$\begin{array}{l}\text { Section } 3 \\
\text { Opinion about } \\
\text { training }\end{array}$} & Q17 & $\begin{array}{l}\text { Have you received sufficient training to understand and address cascading events } \\
\text { and interdependency of services? }\end{array}$ \\
\hline & & Are you aware of methodologies such as: \\
\hline & Q18a & Wider impact analysis and impact trees \\
\hline & Q18b & Other forward-looking tools \\
\hline & & $\begin{array}{l}\text { How useful do you think the following training on cascading events and their } \\
\text { interdependencies might be? }\end{array}$ \\
\hline & $19 \mathrm{a}$ & An intensive course for public utility services \\
\hline & $19 \mathrm{~b}$ & Roundtable events or table top exercises \\
\hline & $19 \mathrm{c}$ & Freely available guidelines \\
\hline & $19 d$ & Webinars and on-line lessons \\
\hline & $19 \mathrm{e}$ & National and trans-national exercises \\
\hline & Q20 & $\begin{array}{l}\text { Is there anything else that has not been mentioned which should be prioritized? } \\
\text { (Open answer) }\end{array}$ \\
\hline \multirow{6}{*}{$\begin{array}{l}\text { Section } 4 \\
\text { Experience and } \\
\text { affiliation }\end{array}$} & Q21 & How would you define your level of experience and proficiency in this sector? \\
\hline & Q22 & $\begin{array}{l}\text { Have you ever participated in training sessions or workshops on cascading or } \\
\text { interdependent events? }\end{array}$ \\
\hline & Q23 & What is your affiliation? \\
\hline & Q24 & Are you: $\square$ Male $\square$ Female $\square$ Other $\square$ Prefer not to say \\
\hline & Q25 & Was this workshop useful for you? \\
\hline & Q26 & Do you have any other comments? (Open answer) \\
\hline
\end{tabular}

Table 1- Items used in the questionnaires, with highlighted multiple questions (grey) and discretionary open answer (yellow). 


\section{Quantitative analysis}

Overall, ANYTOWN was very well attended by local stakeholders. It had 74 participants, 69 without the event coordinators, filling the room available at the London City Hall in both sessions. The workshop had good gender balance, with slightly more female representatives (33 males and 40 females). The full institutional support of LR, LCCP, and TfL, allowed thecollection 57 questionnaires which were equivalent to a response rate of approximately $82 \%$ of participants. The forms were considered valid if at least $70 \%$ of the mandatory answers were completed, in line with the standard quantitative methodology described earlier, reducing the analysis to 54 questionnaires. This small drop is likely to be associated with the fact that many stakeholders were available for emergency calls or had pre-scheduled meetings, inducing some of them to leave the room before the end of the event. The next sections describe the distribution of the frequencies for each part of the questionnaire, analysing separately their correlations.

\subsection{Perceptions of cascading events and interdependencies}

The respondents unanimously agreed that cascading events are extremely relevant to emergency management $(M=4.7, S D= \pm 0.5)$. Despite the common perception that loss of essential services could be very risky to life and personal safety or security $(M=4.57, S D= \pm$ 0.49), the answers highlighted that disruptions were just somewhat catered for in UK emergency management $(M=3.31, S D= \pm 0.67)$. In particular, cascading events and interconnected failures were only marginally prioritized both in existing policies $(M=2.88$ $S D= \pm 0.58)$, and practices $(M=2.81, S D= \pm 0.68)$. Similarly, the respondents perceived a lack of integration in the existing agreements for cross-border crisis management, such as the deployment of the EU civil protection machinery $(M=2.57, S D= \pm 0.95)$. However, the value of the standard deviation suggests some more fragmentation in the average values, with a consistent per cent of missing responses (13\%). The lack of shared agreement on this item could be easily explained by the fact that the operational role of many participants did not necessarily required the knowledge of cross-border drivers. Finally, the questionnaire pointed out that a common definition of 'tipping points' and acceptable risk is be needed $(M=3.76$, $S D= \pm 0.77)$, while it was agreed that cascading events could become more common because of climate change $(M=4, S D= \pm 0.76)$. In both cases, slightly more than a half of the answers were concentrated in the highest values of the Likert Scale. Figure 1 provides a graphical overview of the perceptions of cascading risk recorded in this section. It points out the contrast between the relevance and possible impacts, the need for training, the potential of its association with climate change, compared to the integration in policies and practices. 


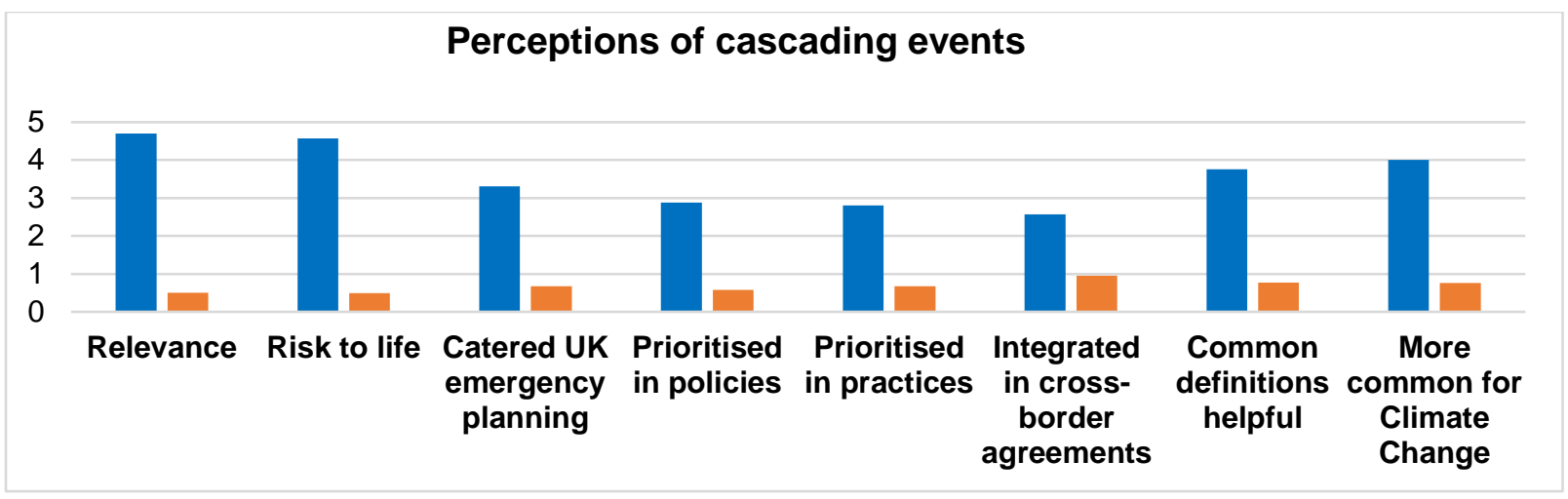

Figure 1 - Perceptions of cascading events and interdependencies (Q1-Q6). The mean is represented in blue and the SD in orange. The values are based on a Likert scale from 1-5, with no answer being 0 and 5 being the most positive value.

\subsection{Perceptions of mitigation strategies}

Scenario building ( $M=4.09, S D= \pm 0.49)$, and contingency planning $(M=4.4, S D= \pm 0.57)$, were unanimously recognized as essential tools to understand cascading events. The other mitigation measures must be investigated more carefully, as all of them were perceived useful but with different levels of fragmentation. There is agreement that better information about the resources needed for contain escalations could improve procurement and response $(M=3.77, S D= \pm 0.73)$. In this case, the valid answers are concentrated in the top tiers but balanced by one third of average answers. In line with the expectations, a very high priority was attributed to the integration hazard risk maps with ranking of $\mathrm{Cl}(\mathrm{M}=4.02, \mathrm{SD}= \pm 0.75)$ and to improvement of intermodal inter-modal coordination $(M=4.07, S D= \pm 0.72)$. In the first case, approximately $77 \%$ of valid answers were cumulated in the top values (4 and 5 ), rising to $85 \%$ for intramodality. Interactive tools and decision support systems were perceived as very useful $(M=4.02, S D= \pm 0.82)$, but with a fragmentation that can be associated with some of the comments. Similar patterns, but with much more variability, are attributed to energy sources $(M=3.75, S D= \pm 0.95)$, which in the frequency table are literally split between some improvement (42\% of valid answers), high improvement (approx. 23\%), great improvement (approx. 29\%). When interrogated about who should assure the consistency of information to the public, the respondents used multiple answers. The government appeared in $82 \%$ of cases ( $39 \%$ standard percent), followed by utilities in $52.0 \%$ of cases ( $28.4 \%$ standard percent) and business $26 \%$ of cases ( $12.4 \%$ standard percent). The category 'other' was used in $22 \%$ of cases, while lower values attributed to NGOs and Academia. Surprisingly, individual responsibility or no need for coordination was indicated in just one answer.

In conclusion, the respondents are only moderately trying to integrate longer term climate change in planning $(M=3.56, S D= \pm 0.86)$, with in some cases additional comments in the open questions. The perceived need for developing international mitigation strategies for cascading events and service disruptions had the lowest values in the section, and it was distinguished also by highest standard deviation $(M=3.07, S D= \pm 1.02)$. The values showed the existence of a wide disagreement amongst the respondents that are nearly equally divided between the high-low peaks. Figure 2 reports the visual output of this last question. 


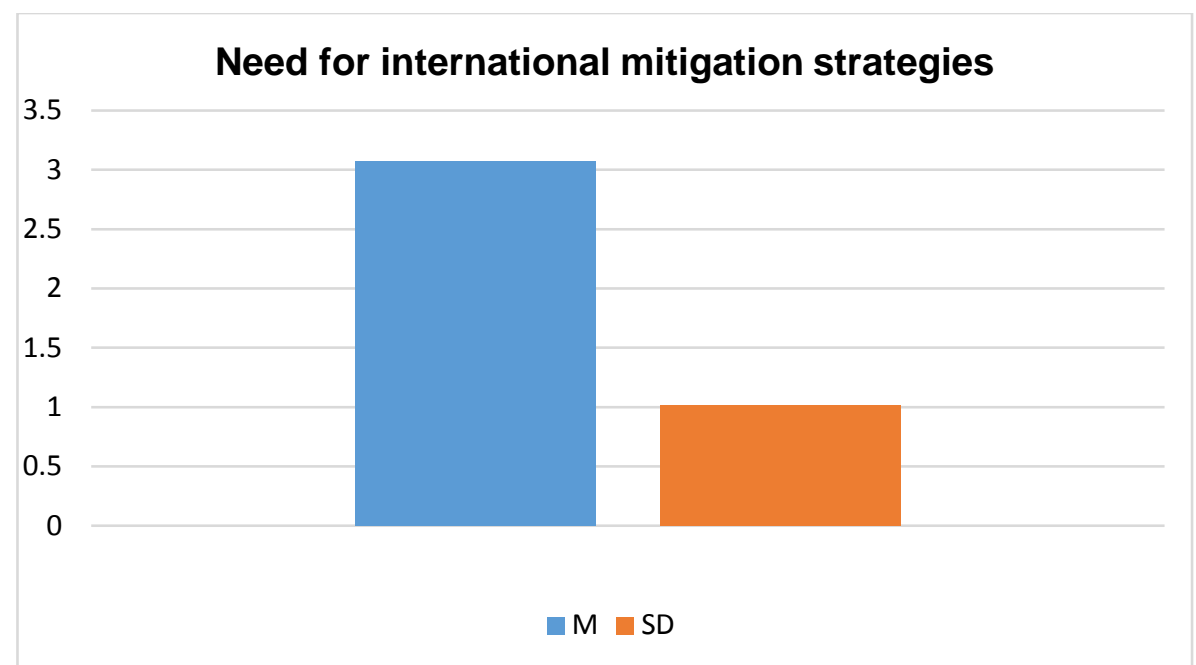

Figure 2 - Overview of two key aspects of mitigation strategies. The mean is represented in blue and the SD in orange. The values are based on a Likert scale from 1-5, with no answer being 0 and 5 being the most positive value.

\subsection{Perceptions of training}

The perceived levels of training among the respondents were just somewhat sufficient, with high fragmentation in the answers that suggests better analysis of target groups ( $M=2.9$, $S D= \pm 1.01$ ). The frequency table points out a slight concentration in the lower tiers, with $10 \%$ of missing answers that in some cases were explained in the comments. However, it is positive to note that most participants were aware of wider impact analysis and impact trees $(73.6 \%$ valid percent), and other forward-looking tools (60.8\%). The most useful options for improving future training were freely available guidelines $(M=3.92, S D= \pm 0.8)$ and tabletop exercises $(M=3.87, S D= \pm 0.68)$. They were followed by intensive courses for public utility services $(M=3.77, S D= \pm 0.85)$ and national and transnational exercises $(M=3.70, S D= \pm 0.79)$. In the first case, approximately $73 \%$ of valid answers were concentrated between very and extremely high values, while the concentration was anyway unequivocal even in the case of the exercises (approx. 62\%). Instead, webinars and online lessons were not perceived so useful and were distinguished by high variation in the answers, discouraging de facto any investment in that option without any understanding of possible target groups ( $M=3.36$, $S D= \pm 1.02$ ). The general high values of the possible training tools suggested clearly the need to undertake actions for improving the situation (Figure 3). 


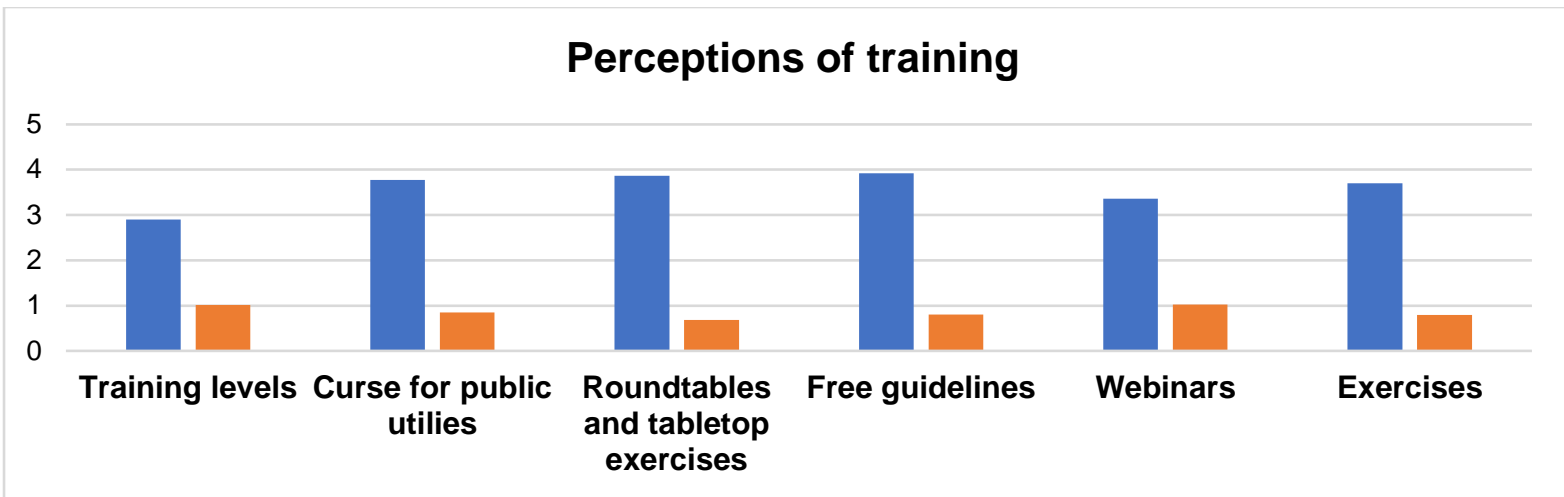

Figure 3 - Perceptions of training(Q17-Q19e). The mean is represented in blue and the SD in orange. The values are based on a Likert scale from 1-5, with no answer being 0 and 5 being the most positive value.

\subsection{Experience, affiliation, and gender}

The respondents were very well distributed amongst all the levels of experience (Figure 4). There was a perfect balance between novices and stakeholders advanced experience $(25 \%$ each), a consistent intermediate level between 3 and 5 years (30.8\%), and a valid representation of experts with more than ten years in the sector (15.4\%). Just a couple of people had basic awareness of the topic, in line with what was expected by the organisers. Most of them (56.6\%) already participated in training workshops on cascading or interdependencies. Most participants were Category 1 responders (40.7\%), intended as core emergency services and local authorities, and Category 2 responders (11.1\%), intended as private sectors bodies such as utilities. These were followed by academia (16.7\%), business not included in Category 2. (14.8\%), other categories (approx. 11.1\%), and with lower participation of NGOs and charities (3.7\%). The gender balance of the registered participants of the workshop was reflected in the responses, that had $52.8 \%$ female respondents and $47.2 \%$ of males. Finally, the ANYTOWN workshop was considered useful by most of participants $(\mathrm{M}=3.77, \mathrm{SD}=0.77)$.

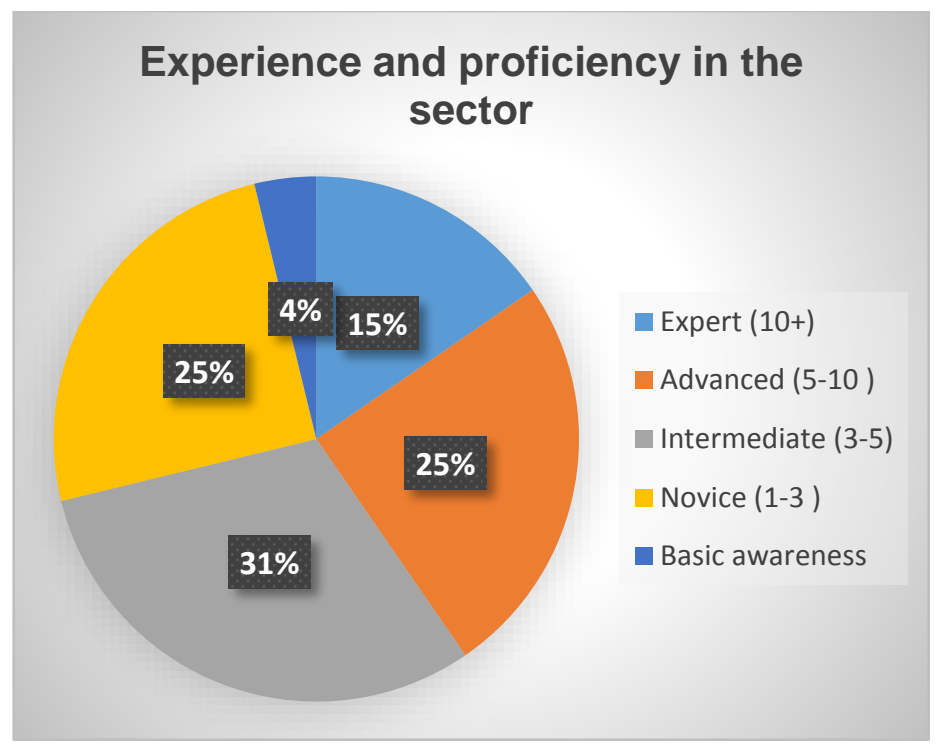

Figure 4- Experience levels among the respondents 


\subsection{Correlations between answers}

The particular nature of the dataset suggested testing the existence of possible correlations among the answers, in order to have a better overview of which items could be associated together (Cohen, 1988; Evans, 1996). However, it must be considered that the final goal of this work is supporting policy making, and not deriving any psychological models for which indepth methodologies, such as regressions, may be needed. Our analysis used Pearson's coefficient to verify the possible consistency between the continuous variables reported in section 1 , section 2 , and section 3 , according to the research goals. The responses were considered significant at the 0.01 level (two tailed), and the effect size was in line with the values used by Evans (1996). Secondly, cross-tabs were used to assess the correspondence between other continuous variables and the ordinal ones such as experience and affiliation. They were preferred to other tests, such as multinomial logistics or Cramer's v, for two key reasons: 1) To maintain a higher accessibility of the content for end-users; 2) To assess the existence of sub groups, that could determine differences in the development of training strategies and targeted work.

\subsubsection{Correlations within sections}

A primary analysis explored if there were any of correlations within the answers of section 1 (Perception of cascading events), 2 (Opinion about mitigation strategies), and 3 (Opinion about training). This was done to verify the existence of possible drivers that could be useful for policy makers, and a synthesis of the output is reported in Table 2 . In section 1 , the results show the existence of a moderate positive relationship between the prioritization of cascading events and interconnected failures in existing policies and practices $(r=0.444, n=51$, $\mathrm{p}=.001$ ). Similarly, a moderate positive relationship was found between the prioritization in policies and the integration in agreements for cross-border management $(r=0.508, n=46$, $p=.000$ ). It can be noted that those results suggest that there was a tendency to have a common view between high prioritization in policies and practices, while the responders that perceived some higher values in policies, believed also that there was more integration at the international level. In section 2, higher values perceived for the integration of hazard risk maps and rankings of $\mathrm{Cl}$ were weakly associated with higher values attributed to the use of localized energy sources for improving resilience $(r=0.366, n=50, p=.009)$. Instead, a moderate correlation was found between the usefulness of improving intermodal transportation and the localized energy sources $(r=0.478, n=52, p=.000)$. These correlations, together with the values of those registered in the previous sections, may suggest that higher value in energy were perceived as part of the interconnected challenges more than a self-standing mitigation. In conclusion, the analysis of section 3 revealed some unexpected trends. A moderate correlation was found between the training received and the perceived utility of roundtable and table top exercises $(r=0.396, n=47, p=.006)$. Intensive courses for public utility services were weakly correlated with training on national and transnational exercises $(r=0.380, n=53$, $p=.005)$, while those had a similar relation with webinars $(r=0.382, n=53, p=.005)$, and moderate correlations with table top exercises $(r=0.491, n=53, p=.000)$. Instead, a strong 
correlation was found between how useful were perceived freely available guidelines and webinars $(r=0.607, n=53, p=.000)$.

\begin{tabular}{|l|l|l|}
\hline Questions and answers correlated within each section & Value (r) & Strength \\
\hline \hline Q4a (policies) and Q4b (practices) & 0.444 & Moderate \\
\hline Q4a(policies) and Q4c (cross-border management) & 0.508 & Moderate \\
\hline Q9 (hazard risk and Cl ranking) with Q11 (localized energy) & 0.366 & Weak \\
\hline Q10 (intermodal transportation) and Q11 (localized energy) & 0.478 & Moderate \\
\hline Q17 (training received) and Q19b (roundtables and exercises) & 0.396 & Moderate \\
\hline Q19a (course for public utility) and Q19e (transnational exercises) & 0.380 & Weak \\
\hline Q19e (transnational exercises) and Q19b (exercise) & 0.491 & Moderate \\
\hline Q19e (transnational exercises) and Q19d (webinars) & 0.382 & Weak \\
\hline Q19c (guidelines) and Q19d (webinars) & 0.607 & Strong \\
\hline
\end{tabular}

Table 2-Correlations within each section of the questionnaire. QN refers to number the full questions reported in Table 1.

\subsubsection{Correlations across sections}

A different analysis was run to understand the correlation across the sections ( 1 to 3 ), with care to understand if training levels were associated to any variations in the opinions about mitigation strategies and risk perceptions. A synthesis table is reported in Table 3, where there can be noted some weak and moderate correlation. The first evidence that emerges is that despite it being expected that the existing training to orient most of the results, there was nothing diffused. Indeed, the general levels of received training were moderately correlated just with the perceived integration of cascading in agreements for cross-border management $(r=0.496, n=45, p=0.001)$. This last item was also moderately correlated with roundtables and table top exercises $(r=0.481, n=46, p=0.001)$, and with the training level on national and transnational exercises $(r=0.422, n=46, p=0.003)$. Surprisingly, the availability of guidelines was weakly correlated with tipping points and acceptable risk ( $r=0.372, n=53$, $p=0.006)$, giving the idea that in case of uncertainties the availability of open source material can make the difference. Instead, there are limited relations between the values attributed to mitigation measures and policies. Contingency planning was weakly associated with the perception that the loss of essential services can cause risk to life and personal safety $(r=0.385, n=54, p=0.004)$. The values attributed to the perception that service disruption require the development of international mitigation strategies were weakly correlated to the perceived prioritisation of cascading risk in policies $(r=385, n=51, p=0.005)$. Finally, as may have been expected, the responders that perceived more cascading events more common as a result of climate change had the tendency to include long term climate change in planning $(r=381, n=50, p=0.006)$.

\begin{tabular}{|l|l|l|}
\hline Questions and answers correlated across sections & Value (r) & Strength \\
\hline \hline Q17 (training received) and Q4c (cross-border management) & 0.496 & Moderate \\
\hline $\begin{array}{l}\text { Q19(roundtables and tabletop exercises) and Q4c (cross-border } \\
\text { management) }\end{array}$ & 0.481 & Moderate \\
\hline Q19e(transnational exercises) and Q4c (cross-border management) & 0.422 & Moderate \\
\hline Q19c(guidelines) and Q5 (tipping points) & 0.372 & Weak \\
\hline Q7b(contingency planning) and Q2 (service disruption and life losses) & 0.385 & Weak \\
\hline Q14(international mitigation strategies) and Q4a (policies) & 0.385 & Weak \\
\hline
\end{tabular}


Q15(long term climate change in planning) and Q6(cascading more common

as result of climate change)

Weak

Table 3- Correlations across the sections of the questionnaire. QN refers to number the full questions reported in Table 1.

\subsubsection{Are experience and affiliation orienting the perception of training and mitigation measures?}

Cross- tabs were used to verify if the values attributed to the training options were associated with any level of experience and proficiency in the sector. In other words, chi-square analysis was used to test any correlation between the levels of experience, risk perceptions, mitigation measures, and training options. This was done to understand the existence of possible target groups, but the test showed low levels of confidence due to a general fragmentation of answers. A similar analysis was applied to test the existence of correlations between the affiliation and the training options. The results showed different levels of statistical confidence, but it was possible some target groups for two forms of training:

1) Courses for utility services presented fragmented answers $\left(\chi^{2}=0.087\right)$, but they were considered tendentially very useful mostly by Cat 1 responders, Cat 2 responders, and academia.

2) Roundtables and table top exercises had less fragmented answers $\left(\chi^{2}=0.058\right)$. It is unequivocal that nearly the total of Category 1 responders perceived this training very useful, and this is true also for Academia, NGOs and others. Category 2 responders were instead quite undecided, and business had the tendency to perceive this training less useful.

However, it must be noted that this result may have been affected by the limited number of representatives of categories such as Nongovernmental, not-for-profit, and religious organization. We recommend further analysis to test each training. Similarly, we decided not to run correlations with $\mathrm{Q} 18 \mathrm{a}, \mathrm{b}$ (wider impact analysis and other forward looking) because the vast majority of the participants knew the tools, and the limitations in the dataset could have influenced the result. In conclusion, Gender did not influence the general perceptions of risk, but we decided not to test this possible influence on mitigation and training. This element could have been interesting in a psychological study, while it could not drive suggestions for decisionmakers for whom now these are mandatory non-discriminatory policies.

\section{Qualitative content analysis: Mitigation, training, and other comments}

The qualitative content analysis (Berg, 2001) offers a complementary overview of stakeholder's perceptions, integrating a bottom up perspective. The comments are categorized following to their sections in the questionnaire (Mitigation, Training, Other), to provide a better framework of the answers.

\subsection{Suggested mitigation strategies}


Approximately a third of the participants (17/54) suggested some mitigation options that were not already included in the questionnaire. Table 4 reports the category of the training suggested, together with the identity of each questionnaire, the affiliation, the participation to previous training (Q22), the experience in the sector, and the transcription of each comment. All the levels of experience and affiliation were represented, although not in the same proportions as the quantitative data. In particular, it must be noted that most of the suggestions (13/17) were made by personnel that already participated in training sessions (Q22), and may have already had a clear idea of what was missing in the current practices and policies. This makes the qualitative analysis of particular relevance, in line with the needs of LR and LCCP, highlighting some common problems reported in the literature (Abrahamsson, Hassel, and Tehler, 2010; Alexander, 2002, 2005, 2016; Alexander, 2015; Lindell, Prater, and Perry, 2007; Perry and Lindell, 2003; Quarantelli, 1997). The coding process, cross-checked with LR to maintain coherence with their operational language, suggests the following areas of improvement:

$\checkmark$ Community resilience. Comments referred to the need for better mitigation strategies aimed to improve local resilience, integrating top down and bottom up approaches, and the specificities of local contexts. The respondents had mixed affiliation and the experience, while $3 / 5$ of them had already participated in training sessions.

$\checkmark$ Coordination. Comments reported one of these coordinations is still a challenge that needs to be solved at all levels. The answers referred to inter-agency protocols, to the central government and the local authorities, but also between protocols of climate change adaptation and emergency preparedness. In this case, $3 / 4$ of the comments were made by Category 1 responders, and allof them participated in training sessions.

$\checkmark$ Knowledge of risk, interdependencies and vulnerabilities. Comments referred to the need to assess better the dynamics associated with the topic of the workshop, and the vulnerability of the system at large. In this case, the answers were just affiliated to academia and Category 2 responders, that for the majority participated intraining and had a polarised experience between novice and advanced.

$\checkmark$ Information sharing and financial support. The information sharing was perceived as an essential element to improve and still not timely enough for business. There was suggested more governmental support in terms of information on how to access funding. The affiliation was mixed, all respondents had training and experience.

\begin{tabular}{|c|c|c|c|c|c|}
\hline $\begin{array}{c}\text { Mitigation } \\
\text { suggested }\end{array}$ & ID & Affiliation & $\begin{array}{c}\text { Trai } \\
\text { ning }\end{array}$ & $\begin{array}{c}\text { Exp. } \\
\text { (years) }\end{array}$ & $\begin{array}{c}\text { Opinion about mitigation strategies } \\
\text { Q16) Is there anything else that should be prioritised? }\end{array}$ \\
\hline \hline & M01 & Cat. 2 & No & $10+$ & "Lessons learned to improve processes". \\
\cline { 2 - 6 } & M16 & Academia & No & $3-5$ & "Difference between local/national +urban/rural context". \\
\cline { 2 - 7 } & M23 & Cat.1 & Yes & $10+$ & $\begin{array}{l}\text { "If we combine fire +police is there a risk of lack of } \\
\text { resources/funding in a major emergency? Community resilience". }\end{array}$ \\
\cline { 2 - 6 } & M25 & Cat.1 & Yes & $1-3$ & $\begin{array}{l}\text { "More public awareness of longer term consequences of sudden } \\
\text { impact events and building community resilience into people } \\
\text { mind sets (The public should no longer expect public sector to } \\
\text { instantly resolve their issues)". }\end{array}$ \\
\cline { 2 - 6 } & A 02 & Cat. 2 & Yes & $3-5$ & $\begin{array}{l}\text { "Culture and behaviour of populations. Training for individuals - } \\
\text { perhaps in conjunction with (word not understandable) services". }\end{array}$ \\
\hline $\begin{array}{c}\text { Coordinatio } \\
\text { n }\end{array}$ & M22 & Cat.1 & Yes & $3-5$ & $\begin{array}{l}\text { "Central government support for when local capacity is exceeded. } \\
\text { How we prepare communities for this risk". }\end{array}$ \\
\hline
\end{tabular}




\begin{tabular}{|c|c|c|c|c|c|}
\hline & A16 & Cat. 1 & Yes & $10+$ & $\begin{array}{l}\text { "More focus on transferable (word not understandable) warning } \\
\text { info inter-agency, cross- warning (or working) }\end{array}$ \\
\hline & A22 & NGO & Yes & $1-3$ & $\begin{array}{l}\text { "Coordination between police, NITS, fire government tv control } \\
\text { communication, operations etc.". }\end{array}$ \\
\hline & A28 & Cat. 1 & Yes & $3-5$ & $\begin{array}{l}\text { "Linking climate change adaptation with emergency } \\
\text { preparedness response arrangements". }\end{array}$ \\
\hline \multirow{5}{*}{$\begin{array}{l}\text { Knowledge } \\
\text { of risk, } \\
\text { interdepend } \\
\text { encies and } \\
\text { vulnerabiliti } \\
\text { es }\end{array}$} & M10 & Cat. 2 & No & $5-10$ & $\begin{array}{l}\text { Do we fully understand all the key risks and (word not clear) the } \\
\text { utility to quantify them?". }\end{array}$ \\
\hline & M12 & Academia & No & $0-1$ & "Key vulnerabilities e.g. food supply routes, mortuary capacity". \\
\hline & M24 & Academia & Yes & $5-10$ & $\begin{array}{l}\text { "Simulation of nonlinear interdependencies and feedback loops } \\
\text { as help to understand consequences, e.g. system dynamics, } \\
\text { system thinking tools etc.". }\end{array}$ \\
\hline & A01 & Academia & Yes & $1-3$ & $\begin{array}{l}\text { "There are still unknown (inter)dependencies that can } \\
\text { cause/affect cascades. Something like route diversion (?) that can } \\
\text { result in railway bridge strikes or water main bursts that can } \\
\text { interrupt transportation services and other business. Not much } \\
\text { data/information/understanding available". }\end{array}$ \\
\hline & A11 & Cat. 2 & Yes & $5-10$ & "Weather effect on civil failures". \\
\hline \multirow{3}{*}{$\begin{array}{l}\text { Information } \\
\text { sharing and } \\
\text { financial } \\
\text { support }\end{array}$} & M19 & Business & Yes & $5-10$ & $\begin{array}{l}\text { "Communication to business and people are key if must be timely } \\
\text { more than } 100 \% \text { accurate }(80 \% \text { often is better than } 100 \% \text { less } \\
\text { often)". }\end{array}$ \\
\hline & A09 & Cat. 2 & Yes & $3-5$ & $\begin{array}{l}\text { "Financial + funding required for info gathering +production of } \\
\text { support systems etc. where is the money going to come from?". }\end{array}$ \\
\hline & A31 & Cat.1 & Yes & $10+$ & $\begin{array}{l}\text { "Guidance for finance, human resources, what would the } \\
\text { government do to assist". }\end{array}$ \\
\hline
\end{tabular}

Table 4- Open answers and categories of "mitigation strategies".

\subsection{Suggested training}

The comments on training werefar fewer, with 10 answers the total of which just 9 were coded. The explanation for the difference in the participation is that the most common options used for training were already included in the questionnaires, as highlighted by one of the respondents (answer not coded). Table 5 reports the training suggested, the identity of the respondents, the affiliation and the comments transcribed from the questionnaire. In this case, the number of participants that had training is well balanced with its overall percentage, while the majority of the comments weremade by Cat. 1 responders. The coding was harder due to the limited number of suggestions, but some general outlines can be derived:

Training and awareness of the public. The comments suggested improving the training of the public, raising awareness. This approach could be in line with the previous answers suggesting the development of mitigation actions on community resilience.

$\checkmark$ Coordination. This is often a structural issue in disaster prevention and management. Some elements were recurrent with the previous table, such as the support of central government planning to local planning, and the need for a multi-agency approach that includes business continuity. Interestingly, it was suggested to consider better the implications of transportation disruptions on the movement of key personnel.

$\checkmark$ Optimised scenario and exercises. Some answers highlighted the relevance of scenario and exercises, in particular "in person" ones, supporting the evidence defined by the quantitative data. However, one comment refers to the need to understand better the lessons learned from the existing training, which is in line with the need for integrating the qualitative commentary in this research. 


\begin{tabular}{|c|c|c|c|c|c|}
\hline $\begin{array}{c}\text { Training } \\
\text { suggested }\end{array}$ & ID & Affiliation & $\begin{array}{l}\text { Trai } \\
\text { ning }\end{array}$ & $\begin{array}{c}\text { Exp. } \\
\text { (years) }\end{array}$ & $\begin{array}{l}\text { Opinion about Training } \\
\text { Q20) Is there anything else that should be prioritised? }\end{array}$ \\
\hline \multirow{2}{*}{$\begin{array}{l}\text { Training and } \\
\text { awareness } \\
\text { of the } \\
\text { public } \\
\end{array}$} & M09 & Cat.1 & No & 3-5 & $\begin{array}{l}\text { "Public awareness campaigns. Public in the UK are ill prepared for } \\
\text { emergencies unless near COMAH included sites". }\end{array}$ \\
\hline & M16 & Academia & No & $3-5$ & "Training for the public too". \\
\hline \multirow{3}{*}{$\begin{array}{l}\text { Coordinatio } \\
\mathrm{n}\end{array}$} & M22 & Cat.1 & Yes & 3-5 & "Central government planning and support for local planning". \\
\hline & A28 & Cat.1 & No & $1-3$ & $\begin{array}{l}\text { "Business continuity } \rightarrow \text { multi-agency approach e.g. to priotising } \\
\text { critical sources across sectors". }\end{array}$ \\
\hline & A 02 & Cat.2 & Yes & 3-5 & $\begin{array}{l}\text { "Considering impacts of movements of key staff outside of } \\
\text { expensive city-centre location and therefore more transportation } \\
\text { required implications". }\end{array}$ \\
\hline \multirow{4}{*}{$\begin{array}{l}\text { Optimised } \\
\text { scenario } \\
\text { and } \\
\text { exercises }\end{array}$} & M23 & Cat.1 & No & $1-3$ & $\begin{array}{l}\text { "More lessons learned. Lots of public reports etc. etc. not } \\
\text { necessarily put into practice". }\end{array}$ \\
\hline & M24 & Academia & Yes & $5-10$ & "Scenario games". \\
\hline & A11 & Cat. 2 & Yes & $5-10$ & "Cat $1+$ Cat 2 exercises and workshops". \\
\hline & A18 & Cat.1 & Yes & $5-10$ & $\begin{array}{l}\text { "Real 'in person' sessions are better than 'virtual as networking + } \\
\text { talking+ listening to colleagues in other professions gives } \\
\text { extended understanding of other priorities/ challenges +needs". }\end{array}$ \\
\hline$N N$ & A31 & Cat.1 & Yes & $10+$ & "None". \\
\hline
\end{tabular}

Table 5- Open answers and categories of "training" . For "training" is intended if the respondent had ever participated in training session or workshops on cascading or interdependent events (Q 22, Table 1).

\subsection{Other comments}

Even when the option "other" in answer 13 is considered (Table 6), most of the comments refer to the need for better integrating of the local communities as pro-active agents instead of mere receptacles of information, while all the actors should act more "together". Indeed, the open option to question 13 on who is in charge of assuring the information does not add much evidence to the quantitative findings. Many of the respondents chose multiple answers and decided to write comments near their options as reported in the last table. The coding was harder due to the limited number of answers, but some general outline can be derived:

Multiple actors at different levels: The majority of respondents in the table marked multiple choices, and commented using the option "other", or the blank space, to highlight the existence of levels of responsibility and coordination dependent on the situation. One referred directly to the role of Gold Commands as a specification of governmental duties.

$\checkmark$ Local resilience forum and partnership: It is interesting to note that some answers referred to resilience forum, devolved institution and partnerships that have a mixed nature, representing a network more than single institutional actors. 


\begin{tabular}{|c|c|c|c|c|c|}
\hline $\begin{array}{l}\text { Q13 } \\
\text { "Other" }\end{array}$ & ID & Affiliation & $\begin{array}{l}\text { Trai } \\
\text { ning }\end{array}$ & $\begin{array}{c}\text { Exp. } \\
\text { (years) }\end{array}$ & $\begin{array}{l}\text { Q13) Who do you think should assure the consistency of } \\
\text { information }\end{array}$ \\
\hline \multirow{10}{*}{$\begin{array}{l}\text { Multiple } \\
\text { actors at } \\
\text { different } \\
\text { levels }\end{array}$} & M10 & Cat.2 & No & $5-10$ & Multiple answers, comment: "at different levels". \\
\hline & M11 & Other & Yes & $3-5$ & $\begin{array}{l}\text { Multiple answers, is specified "transport companies" that should } \\
\text { be business. }\end{array}$ \\
\hline & M16 & Academic & No & $3-5$ & Multiple answers, it is specified "with a coordinated routine". \\
\hline & M17 & Cat.1 & Yes & $10+$ & $\begin{array}{l}\text { Multiple answers, it is specified "The lead agency who declares } \\
\text { major incident". }\end{array}$ \\
\hline & M14 & $\begin{array}{c}\text { Cat.1/aca } \\
\text { demic }\end{array}$ & Yes & $3-5$ & $\begin{array}{l}\text { Marked just other: "the owner of the risk should /does own the } \\
\text { communication. and multi-agency platform uniform the } \\
\text { message". }\end{array}$ \\
\hline & A 11 & Cat.2 & Yes & $5-10$ & Multiple answers, comment: "joint". \\
\hline & A 16 & Cat.1 & Yes & $10+$ & $\begin{array}{l}\text { Multiple answers, comment "It could be all depends on } \\
\text { situations. I would want SME's to deliver info- not police talking } \\
\text { fire brigade stuff!" All the options are marked together. }\end{array}$ \\
\hline & A 18 & Cat.1 & No & $3-5$ & $\begin{array}{l}\text { Multiple answers. Comment "Together. Health authorities in } \\
\text { relation with partners". }\end{array}$ \\
\hline & A 19 & Cat.1 & No & $1-3$ & $\begin{array}{l}\text { Multiple answers, comment. "All- Joint agreement of messaging } \\
\text { required". }\end{array}$ \\
\hline & A25 & Cat.1 & No & $1-3$ & Multiple answers, comment "London Gold Comms. Group". \\
\hline \multirow{3}{*}{$\begin{array}{l}\text { Local } \\
\text { resilience } \\
\text { forum and } \\
\text { partnership }\end{array}$} & M23 & Cat.1 & No & $1-3$ & Government and "Local resilience forums". \\
\hline & A09 & Cat.2 & No & $1-3$ & "Local devolved institutions". \\
\hline & A 12 & NGO & No & $3-5$ & "Resilience partnership". \\
\hline
\end{tabular}

Table 6- Comments reported in the section "other" of Question 13, "who do you think should assure the consistency of information".

Finally, Table 7 reports other comments included in the questionnaire that can support the interpretation of the answers. There was a limited numberof adds-ons, and three categories were identified:

Climate Change: the comments, made by Cat. 1 responders, mostly referred to the problems of understanding medium term impacts that can be seen in contrast with immediate priorities, in particular in situations of budget cuts.

$\checkmark$ Guidance on training: two comments highlighted preferences in training. A member of business pointed out the usefulness of tabletop exercises, while the cross tabs suggest some slightly more negative perceptions of this training for this category. Instead, a Cat. 1 responder confirmed the usefulness of guidelines and the contrast with webinars in line with the frequency distribution.

In conclusion, it is needed to add the category "other" for two specifications that could be of use: In correspondence of a high value attributed to DSS as mitigation tool it was reported that its limit was "unless GPS collapse", while a member of academia highlighted the availability of statistical methods as forecasting tools.

\begin{tabular}{|c|c|c|c|c|c|}
\hline $\begin{array}{c}\text { Q13 } \\
\text { "Other" }\end{array}$ & ID & Affiliation & $\begin{array}{c}\text { Trai } \\
\text { ning }\end{array}$ & $\begin{array}{c}\text { Exp. } \\
\text { (years) }\end{array}$ & Other comments \\
\hline $\begin{array}{c}\text { Climate } \\
\text { Change }\end{array}$ & M08 & Cat.1 & No & $3-5$ & $\begin{array}{l}\text { Referring to Q15 on integration of climate change in planning } \\
\text { view that - does not happen as much as it should. There is still a } \\
\text { 4-5 years planning dates". }\end{array}$ \\
\hline
\end{tabular}




\begin{tabular}{|c|c|c|c|c|c|}
\hline & A16 & Cat.1 & Yes & $10+$ & $\begin{array}{l}\text { Referring to Q15 on integration of climate change in planning } \\
\text { specifies "limited budgets create limited opportunities for such } \\
\text { long-term planning". }\end{array}$ \\
\hline & M14 & $\begin{array}{l}\text { Cat.1/acade } \\
\text { mic (other) }\end{array}$ & Yes & $3-5$ & $\begin{array}{l}\text { "Need a definition on cascading events and secondary impacts } \\
\text { emergency response plan and preparedness to all events - } \\
\text { climate induced or man-made. Cat } 1 \text { and } 2 \text { responders are well } \\
\text { trained and experienced in response and communication. No } \\
\text { focus on climate change as priority is immediate life -saving". }\end{array}$ \\
\hline \multirow{2}{*}{$\begin{array}{l}\text { Guidance } \\
\text { on } \\
\text { training }\end{array}$} & M19 & Business & Yes & $5-10$ & $\begin{array}{l}\text { Specifies that roundtables and table top exercises (Q19b) are } \\
\text { the "most useful" training. }\end{array}$ \\
\hline & A 31 & Cat.1 & Yes & $10+$ & $\begin{array}{l}\text { Specifies that guidelines (Q19c) are "very useful especially for } \\
\text { planners", While webinars (Q19d) "not useful at all" because of } \\
\text { "no time". }\end{array}$ \\
\hline \multirow[t]{2}{*}{ Other } & M15 & Academic & Yes & $3-5$ & $\begin{array}{l}\text { It specifies that "thresholds are important and using subjective } \\
\text { terms could cause more confusion", referring to Q5. Moreover, it } \\
\text { specifies the role of "Bayesian and Markovian networks mapping } \\
\text { the interdependencies" as methodological options together with } \\
\text { impact trees and forward-looking tools. }\end{array}$ \\
\hline & M16 & Academic & No & $3-5$ & $\begin{array}{l}\text { The value of Decision support systems I high "Unless GPS } \\
\text { collapse!". }\end{array}$ \\
\hline
\end{tabular}

Table 6 - Answers to "other" comments, that correspond to Q26 as reported in Table 1.

\section{Discussion}

Our evidence confirms the hypothesis that the current crisis management approach to cascading risk is inadequate. London's stakeholders are concerned and aware of the relevance of cascading events and interdependencies, that are perceived as threats to life without being sufficiently incorporated in the current policies, practices, and emergency management at large. There is more awareness about the need to create a paradigm shift toimprove the resilience to cascades and complex events, but this is far for being fully implemented (Helbing 2013; Linkov et al. 2014). However, while many gaps confirmed thefirst hypothesis, the results suggested also a slight improvement of the situation if compared to the evidence provided by Luiijf and Klaver (2013). It is clear that the definitions of operational tipping points and uncertainties are critical challenges that need immediate actions, although they are recurring issues highlighted in the literature on the 2010 ash cloud, environmental change, and cascading effects (Alexander 2013; Amon et al. 2016; Scaini et al. 2015; Wardekker et al. 2008). On the one hand, the definition of tipping points and uncertainties could increase the flexibility of response, in line with the need for specifying priorities and inter-organisational coordination highlighted as critical elements for emergency planning by Perry and Lindell (2003). On the other hand, contingency planning and scenario building were considered the solid bases for providing a better understanding of cascades, and could be used to increase the flexibility to uncertainties and the escalation of secondary crises as argued by different authors (Alexander 2016; Münzberg et al. 2017; Pescaroli and Alexander 2016). Finally, the respondents believed that cascading events could become more common as a result of climate change as is recognised in the literature due to the increased pressure on the built environment, leadership and on society (Galaz et al. 2011; Linkov et al. 2014). Most mitigation measures received high values in the responses, confirming the hypothesis that improvements on the status quo are urgently needed. Itis commonly perceived that hazard risk maps and critical infrastructure rankings should be integrated in the broader 
legislation (Nones and Pescaroli 2016), as well as improvements in intermodal coordination (Alexander 2013). The value attributed to decision support tools ishigh, and could be associated with the need to assure communication and exchange of information that could be vital in complex emergencies (Scaini et al. 2015; Setola et al. 2016; Ulfarsson and Unger 2011). This seems to be confirmed by some of the qualitative answers about mitigation measures. The knowledge of interdependencies was a critical point also in the qualitative comments, but mostly within the academic community and Cat. 2 responders more than Cat. 1 responders which may suggest reflecting better on the target groups for which each strategy is settled. Moreover, the responders attribute some priority to the need for improving information for optimising procurement strategies and deployment, as well as for the integration of the local energy supply for increasing $\mathrm{Cl}$ resilience. This was quite surprising, because we expected much higher values and shared agreement on those two items. The result is not low enough to contradict the literature (Helbing 2015; Pescaroli and Kelman 2017; Petermann et al. 2011), but further investigations should be made to understand if those measures are more context dependent than what believed. Some separate considerations must be made about the perceived need for international mitigation strategies, where the values were very low and completely different from what could have been expected. There is an unequivocal misunderstanding of the cross-border dimension of cascades, aspects of which have been described widely in the literature (Boin and McConnell 2007; Ansell et al. 2010; Galaz et al. 2011). This may be associated with different operational roles that do not necessarily provide a vision of the bigger picture, but also influenced by training levels as verified with the analysis of correlations.

The qualitative answers proposed a complementary point of view about mitigation measures. The respondents consistently pointed out that knowledge of risk, interdependencies and vulnerabilities must be associated with a better work on community resilience, coordination and information sharing. Again, therewas highlighted the need for more shared responsibility of emergency management and more dialogue between the local and the national level. These are well known issues for the emergency management community that developed criteria and framework such as the work of Quarantelli (1997), Alexander (2002;2005), Boin and McConnell (2007), and Abrahamsson et. al. (2010). These should be applied also in mitigating cascading risk, using the need for renewal to improve and evolve the existing system. The low level of participation of NGOs and charities suggests that further steps are needed in that direction both in policy, practice and future researches. Some other points highlighted open issues in linking climate change adaptation in emergency planning, both in terms of uncertainties about longer term impacts, and possible coordination issues as commonly agreed in the literature (Wardekker et al. 2008, Linkov et al. 2014).

The low average values attributed to training levels contrasted with the high value reported for all the tools of improvement, and in line with our expectations the responses defined the need for further work. It seems that the priority should be attributed to increase the dialogue and availability of information for improving inter-agency coordination, which is one of the critical points suggested by Perry and Lindell (2003). Open access guidelines could be considered a feasible tool to support this process. Moreover, the good values attributed to training and exercises may be in line with the positive effects registered by Parker (2015), after the 2010 eruption, and more in general with the basic strategies adopted for improving emergency management (Lindell et al. 2007). Even in this case, the open answers supported the idea the need for improving the involvement of the public and the coordination process (Quarantelli 1997; Alexander 2002;2005, and Abrahamsson et. al. 2010). They also stated very 
clearly the role of scenario and exercises for understanding better cascades as suggested recently (Pescaroli and Alexander 2016, Alexander 2016, Pescaroli et al. 2018). However, it must be noted that the knowledge of wider impact analysis, impact trees and other forwardlooking tools suggested by Mc Farlane (2015) was much better than expected. This may confirm again that a process of change may be in progress at least in our case study, shifting slightly from what was suggested by Luiijf and Klaver (2013).

In conclusion, the analysis of correlations does not add consistent evidence for the discussion. The limited strengths that we registered in the tables may be oriented by the size of the dataset, that further analysis should be done in that direction. However, there can be noted a constant influence of the training received by the respondents with the perceptions of cross -border management. In other words, the cross-border element of cascading risk is something more associated with training levels as it does not necessarily enter in the operational routines of stakeholders. This is in line with the evidence that training is a vital support for understanding the bigger picture of emergencies and disaster (Alexander 2002;2005; Lindell et al. 2007), and it could be useful to produce a better understanding of the cross-border component of cascading crisis among the respondents. In conclusion, the stronger correlation recorded was between the values attributed to possible training tools such as free guidelines and webinars, which were the most and the least popular options. This may be associated with the fact that the two things are often complementary, for example in the training provided by the United Nations, but in a situation of limited resources these data may suggest concentrating the budget on the better perceived option as the target may be the similar. Further research should investigate this aspect, while in the next section we draw some general conclusions from this study and recommendations from this study.

\section{Conclusions}

This research investigated the perceptions of cascading events and interdependencies among London's stakeholders, and provided evidence to support actions for improving policies and operational resilience. Our analysis highlighted that cascades were perceived as a very relevant threat for society and emergency management, but further work is needed for adapting mitigations and training strategies. The diffused perception that the loss of services can cause risk to life has strong implications for multi-agency coordination: disruptions can be seen as directly challenging the core mission of emergency services, like other conventional threats such as floods. De facto, our data show that cascades cannot be considered anymore as marginal topics and need to be better catered for in emergency planning, including considerations on their relationship with climate change. It is strongly needed to evolve policies and practices, developing an agenda that should include some key strategic actions:

$\checkmark$ Improving intermodal coordination at the local, national and cross-national levels, which has been a lesson not applied from the 2010 ash cloud;

$\checkmark$ Integrating hazard risk maps and critical infrastructure maps, using existing frameworks such as the European floods directive;

$\checkmark$ Promoting definitions of tipping points and acceptable risk for supporting multi-agency coordination, linking climate change adaptation and preparedness arrangements, and clarifying the attribution of responsibilities in the scenario of high uncertainties; 
$\checkmark$ Including community resilience, training of the citizens, and the involvement of pro-active resilience actors in the planning and management of cascading risk;

$\checkmark$ Investing in table-top exercises and guidelines for end users, developing scenario building and contingency planning, and supporting the awareness of interdependencies with the use of Decision Support Systems;

$\checkmark$ Using training to strengthen the cross-border component of cascading risk, including adaptation to climate change drivers as part of emergency preparedness;

$\checkmark$ Improve the discussion on the possible use of localized energy sources and on which datasets on the resources needed to contain extended services disruptions.

Our data set has limitations, but they do not invalidate the results, while suggesting new steps for future researches. We are aware that expert judgment must be used with care, as it can introduce subjectivities and cultural biases into the assessment (Skjong and Wentworth 2001). We mitigated this issue piloting the questionnaire, using together descriptive and numeric Likert scales, explaining the concepts at the beginning of the workshop, and adapting a mixed method approach. However, the limitations of assessing risk perceptions remains. It must be considered that the results could have been influenced by the synergies with ANYTOWN in different ways.

First, it cannot be excluded that organizations with higher awareness of cascading and interdependencies could have been keener to support the participation of their personnel. This factor seems to have a limited impact on our dataset because the distribution of frequencies on previous training and participation to other workshops suggest that the respondents were mixed. Further research should consider a focus on how organisational culture could influence the preparedness to cascades in order to highlight possible gaps and inconsistencies that need guidance from coordination agencies.

Secondly, the initial focus on transportation could have attracted some sort of "sectorial" expertise, influencing the answers on mitigation measures. Even in this case, in our data this component seems to be mediated by the cross-cutting interest registered in the workshop and by the strong involvement of Category 1 responders. We would recommend that further steps should be made to explore the differences between organisations and categories of responders, including a better perspective of small- medium enterprises, charities and NGOs whose participation to the workshop was limited.

Thirdly, using London as a case study presented the advantage of accessing a mixed target group that otherwise could have been very hard to involve in this type of research. The collaboration with LR and LCCP allowed the unique opportunity to develop an integrative research process, accessing stakeholders that otherwise may have not been so collaborative. The unique level of global interdependencies concentrated in London was an essential part of this process, as it determined the existing projects of the authority. However, it may be considered also a limitation. How much does London's ranking in the global cities influence the risk perception of stakeholders? Are data elsewhere still more in line with the evidence provided by Luiijf and Klaver (2013)? It could be desirable to replicate this study in different environments to understand the variations in risk perceptions, testing possible differences between rural and urban areas to promote new coordinated measures for operational resilience.

In conclusion, it must be noted that this research does not pretend to be exhaustive, but it consolidates the basis for further cross-disciplinary analyses. For example, this paper did not 
investigate the psychometric dimensions of cascading risk because it was decided with these stakeholders to focus on other and more "basic" aspects. It could be argued that a better analysis of the psychological drivers could be another element to investigate in the future, exploring other correlations and defining specific target groups for training and policies. Future research may benefit also from a wider use of qualitative methodology, such as semistructured interviews and focus groups, that in this case were not feasible because of time and resource constraints. A final and critical point that should be addressed involves the citizens' perception of cascades to understand how to increase the preparedness of society and to produce timely responses in case of disruptions. Are citizens' priorities changing and influencing what they expect from emergency services? It could be argued that cascading events and interdependencies cannot be intended anymore as one of the many aspects of emergency planning and management, but must be seen as a constant background that will orientate future disaster risk reduction from citizens to planners. There is a long way forward to achieve effective policies, mitigation, and training for a complex and fast evolving context.

\section{Acknowledgements}

This work had been supported by the UCL Knowledge Exchange Award and by the UCL Institute for Risk and Disaster Reduction. The research was not possible without the essential collaboration and experience ofMatt Hogan (London Resilience), Kristen Guida (London Climate Change Partnership), Alex Townsend-Drake (London Resilience), and Prof. David Alexander (UCL). The author gratefully acknowledges Dr. Bayes Ahmed (UCL), Dr. Serena Tagliacozzo (UCL), and Angela Cooper (UCL) for their feedbacks and help. Finally, the comments of Prof. Arjen Boin (Leiden University), Donald Blondin (Donald Blondin), Wout Broekema (Leiden University), and Christian Kalbassi (FDJP) were fundamental for improving the first version of this paper. References

Abrahamsson, M., Hassel, H., and Tehler, H. (2010). Towards a systems-oriented framework for analysing and evaluating emergency response. Journal of Contingencies and Crisis Management, 18(1): 14-25.

Alexander, D. E. (2013). Volcanic ash in the atmosphere and risks for civil aviation: A study in European crisis management. International Journal of Disaster Risk Science, 4(1): 9-19.

Alexander, D. E. (2002). Principles of Emergency Planning and Management. Harpenden, UK: Terra and Oxford University Press.

Alexander, D. E. (2005). Towards the development of a standard in emergency planning. Disaster Prevention and Management : An International Journal, 12(2):158-175.

Alexander, D. E. (2015). Evaluating of civil protection programmes, with a case study from Mexico. Disaster Prevention and Management, 24(2): 263-283.

Alexander, D. E. (2016). How to write an emergency plan. London: Dunedin Academic Press.

Amon, F., Svensson, S., Lindström, J., Ronchi, E., Lindström, P., et al. (2016). Decision-making and human behavior in emergencies with cascading effects-CascEff Report D3.2. CascEff FP7, www.casceff.eu. Accessed 31 October 2017.

Ansell, C., Boin, A., and Keller, A. (2010). Managing transboundary crises: Identifying the building blocks of an effective response system. Journal of Contingencies and Crisis Management, 18(4): 195-207.

Argenti, F., Landucci, G., and Reniers, G. (2016). Probabilistic Vulnerability Assessment of Chemical Clusters Subjected to External Acts of Interference. Chemical Engineering 
Transactions, 48: 691-696.

Birkmann, J., Kienberger, S., Alexander, D.E. (2014). Assessment of Vulnerability to Natural Hazards. Elsevier, London.

Boin, A., and McConnell, A. (2007). Preparing for critical infrastructure breakdowns. Journal of Contingencies and Crisis Management, 15(1): 50-59.

Boynton, P. M., Greenhalgh, T. (2004). Selecting,designing and developing your questionnaire. BMJ, 328 (7451): 1312-1315.

Brown, S. (2010). Likert Scale Examples for Surveys. lowa State University, www.extension.iastate.edu. Accessed 31 October 2017.

Civil Aviation Authority (2014). Passenger welfare at times of major disruption - guidance for UK airports. CAA, London, www.publicapps.caa.co.uk. Accessed 31 October 2017.

Cohen, J. (1988). Statistical Power Analysis for the Behavioral Sciences. Elsevier, London.

Cornell, S., Berkhout, F., Tuinstra, W., Tàbara, J. D., Jäger, J., et al. (2013). Opening up knowledge systems for better responses to global environmental change. Environmental Science and Policy, 28: 60-70.

Egan, M. J. (2007). Anticipating future vulnerability: Defining characteristics of increasingly critical infrastructure-like systems. Journal of Contingencies and Crisis Management, 15(1): 4-17.

Evans, J. D. (1996). Straightforward statistics for the behavioral sciences. Brooks/Cole Publishing, Pacific Grove, CA.

Galaz, V., Moberg, F., Olsson, E., Paglia, E., and Parker, C. (2011). Institutional and political leadership dimensions of cascading ecological crises. Public Administration, 89(2): 361380.

Galbusera, L., Azzini, I., Jonkeren, O., and Giannopoulos, G. (2016). Inoperability Input-Output modeling : Inventory optimization and resilience estimation during critical events. ASCEASME Journal of Risk and Uncertainty in Engineering Systems, Part A: Civil Engineering, 2(3): 1-10.

Helbing, D. (2013). Globally networked risks and how to respond. Nature, 497(7447): 51-59.

Helbing, D. (2015). Responding to complexity in socio-economic systems: How to build a smart and resilient society? SSRN Electronic Journal, March 2015, 23-31.

Helbing, D., Ammoser, H., and Kühnert, C. (2006). Disasters as extreme events and the importance of network interactions for disaster response management. Extreme Events in Nature and Society, 319-348.

Jonkeren, O., Azzini, I., Galbusera, L., Ntalampiras, S., and Giannopoulos, G. (2015). Analysis of critical infrastructure network failure in the European Union: A combined systems engineering and economic model. Networks and Spatial Economics, 15(2): 253-270.

Krausmann, E., and Baranzini, D. (2012). Natech risk reduction in the European Union. Journal of Risk Research, 15(8): 1027-1047.

Labaka, L., Hernantes, J., and Sarriegi, J. M. (2016). A holistic framework for building critical infrastructure resilience. Technological Forecasting and Social Change, 103:21-33.

Lindell, M., Prater, C., and Perry, R. (2007). Introduction to Emergency Management. John Wiley and Sons, Hoboken, NJ.

Linkov, I., Bridges, T., Creutzig, F., Decker, J., Fox-Lent, C., et al. (2014). Changing the resilience paradigm. Nature Climate Change, 4(6): 407-409.

Little, R. G. (2002). Controlling cascading failure: Understanding the vulnerabilities of interconnected infrastructures. Journal of Urban Technology, 9(1): 109-123.

Luiijf, E., and Klaver, M. (2009). Insufficient Situational Awareness about Critical 
Infrastructures by Emergency Management. Proceedings of the NATO Symposium on C3I for Crisis, Emergency and Consequence Management, Bucharest 11-12 May 2009, 1-10. Luiijf, H. A. M., and Klaver, M. H. A. (2013). Expand the Crisis? Neglect Critical Infrastructure! Proceedings of the CRISE 2013, May 27.-29 2013, Weimar, Germany, 293-304.

Macfarlane, R. (2015). Decision support tools for risk, emergency and crisis management: An overview and aide memoire. Emergency Planning College, Vol. 1, London, www.epcresilience.com. Accessed 31 October 2017.

May, F. (2007). Cascading disaster models in Postburn flash flood. In B. W. Butler and W. Cook (Eds.), Proceedings of The Fire Environment - Innovations, Management and Policy; Conference, pp. 446-463). US Department of Agriculture Forest Service, www.fs.fed.us. Accessed 31 October 2017.

Münzberg, T., Wiens, M., and Schultmann, F. (2017). A spatial-temporal vulnerability assessment to support the building of community resilience against power outage impacts. Technological Forecasting and Social Change, 121:99-118.

Nieuwenhuijs, A., Luiijf, E., and Klaver, M. (2008). Modeling dependencies in Critical Infrastructures. In E. Goetz and S. Shenoi (Eds.), Critical infrastructure protection, 205214.

Nones, M., and Pescaroli, G. (2016). Implications of cascading effects for the EU Floods Directive. International Journal of River Basin Management, 14(2): 195-204.

OECD. (2011). Future global shocks. OECD, Paris, www.oecd.org. Accessed 31 October 2017.

Parker, C. F. (2015). Complex negative events and the diffusion of crisis: Lessons from the 2010 and 2011 icelandic volcanic ash cloud events. Geografiska Annaler, Series A: Physical Geography, 97(1): 97-108.

Perrow, C. (1999). Normal accidents:Living with high risk technologies -Updated edition. Princeton University Press, Princeton, PJ.

Perry, R. W., and Lindell, M. K. (2003). Preparedness for Emergency Response : Guide- lines for the Emergency Planning Process. Disasters, 27(4): 336-350.

Pescaroli, G., and Alexander, D. E. (2015). A definition of cascading disasters and cascading effects: Going beyond the "toppling dominos" metaphor. Planet@Risk, Global Forum Davos, 3(1): 58-67.

Pescaroli, G., and Alexander, D. E. (2016). Critical infrastructure, panarchies and the vulnerability paths of cascading disasters. Natural Hazards, 82(1): 175-192.

Pescaroli, G., and Kelman, I. (2017). How critical infrastructure orients international relief in cascading disasters. Journal of Contingencies and Crisis Management, 25(2):56-67.

Pescaroli, G., Wicks, R.T., Giacomello, G., Alexander D.E. (2018) Increasing resilience to cascading events: The M. OR. D. OR. scenario. Safety Sciences, https://doi.org/10.1016/j.ssci.2017.12.012

Petermann, T., Bradke, H., Lüllmann, A., Poetzsch, M., and Riehm, U. (2011). What happens during a blackout. Office of Technology Assessment at the German Bunderstag, Berlin.

Peters, K., Buzna, L., and Helbing, D. (2008). Modelling of cascading effects and efficient response to disaster spreading in complex networks. International Journal of Critical Infrastructures, 4(1/2): 46-62.

Quarantelli, E. L. (1997). Ten criteria for evaluating the management of community disasters. Disasters, 21(1):39-56.

Rinaldi, B. S. M., Peerenboom, J. P., and Kelly, T. K. (2001). Identifying, understanding, and analyzing critical infrastructure interdependencies. IEEE Control Systems, 21(6): 11-25.

Scaini, C., Bolić, T., Folch, A., and Castelli, L. (2015). Civil aviation management during 
explosive volcanic eruptions: A survey on the stakeholders' perspective on the use of tephra dispersal models. Journal of Volcanology and Geothermal Research, 294: 25-36.

Setola,R., Rosato, V., Kyriakides, E., Rome E. (2016). Managing the Complexity of Critical Infrastructures. Studies in Systems, Decision and Control book series, 90, SpringerLink.

Slovic, P., and Weber, E. U. (2002). Perception of risk posed by extreme events. Center for Decision Sciences (CDS) Working Paper, Columbia University.

Sornette, D. (2009). Dragon-kings, black swans, and the prediction of crises. International Journal of Terraspace Science and Engineering, 2(1): 1-18.

Uk Cabinet Office. (2013). Emergency response and $r$ ecovery: Non statutory guidance accompanying the Civil Contingencies Act 2004. London, www.gov.uk, Accessed 31 October 2017.

Ulfarsson, G. F., and Unger, E. a. (2011). Impacts and Responses of Icelandic Aviation to the 2010 Eyjafjallajökull Volcanic Eruption. Transportation Research Record: Journal of the Transportation Research Board, 2214(1): 144-151.

Wardekker, J. A., van der Sluijs, J. P., Janssen, P. H. M., Kloprogge, P., and Petersen, A. C. (2008). Uncertainty communication in environmental assessments: views from the Dutch science-policy interface. Environmental Science and Policy, 11(7): 627-641.

Axinn, W. G., \& Pearce, L. D. (2006). Mixed method data collection strategies. Cambridge University Press.

Berg, B. L. (2004). Methods for the social sciences. Qualitative Research Methods for the Social Sciences. Boston: Pearson Education.

Bryman, A. (2012). Sampling in qualitative research. Social research methods, 4, 415-429.

Van Evera, S. (1997). Guide to methods for students of political science. Cornell University Press.

Palinkas, L. A., Aarons, G. A., Horwitz, S., Chamberlain, P., Hurlburt, M., \& Landsverk, J. (2011). Mixed method designs in implementation research. Administration and Policy in Mental Health and Mental Health Services Research, 38(1), 44-53. 